\title{
Modeling and experimental validation of flow phenomena for optimum rotor blades of a new type permanent magnet generator
}

\author{
Mustafa Illbaş ${ }^{1} \mathbb{D} \cdot$ Mustafa Demirci ${ }^{1}$ (D) Erol Kurt $^{2}$ (I)
}

Received: 7 August 2019 / Accepted: 29 October 2019/ Published online: 4 November 2019

(c) Springer Nature Switzerland AG 2019

\begin{abstract}
In this study, flow phenomena through the axial fan and the rotor dynamic performance analysis of a permanent magnet generator with three phases has been explored for a wide velocity range by using an Ansys-Fluent computational fluid dynamics package. In this respect, velocities of dependence angle for a flat blade have been analyzed, numerically. The self-sustained air cooling performance has been optimized in order to provide more efficient machine, namely the number of blades and blade angles have been considered as different input parameters in the simulations. As a result of simulations, the optimum flat angle of the blade is determined after having the highest velocity value from the outlet of the simulation. Besides, the rotor fan power is obtained from the pressure differences between the inlet and outlet. According to the results, the highest velocity has been predicted as $1.86 \mathrm{~m} / \mathrm{s}$ and power has been calculated as $0.48 \mathrm{~W}$ at 65 degrees of blade. In addition, the optimum number of blade has been ascertained as 40 and the velocity for this blade geometry has been found as $1.39 \mathrm{~m} / \mathrm{s}$. Consequently, the optimum rotor blade angle and number have been determined as 65 degrees and 40, respectively.
\end{abstract}

Keywords Axial fan · Flow phenomena $\cdot$ Computational fluid dynamics $\cdot$ Rotor dynamics

$\begin{array}{ll}\text { Abbreviations } \\ \text { CFD } & \text { Computational fluid dynamics } \\ \text { PM } & \text { Permanent magnet } \\ \text { NdFeB } & \text { Neodium } \\ \text { VAWT } & \text { Vertical axis wind turbines } \\ \text { AFPMSG } & \text { Axial flux permanent magnet synchronous } \\ & \text { generator }\end{array}$

\section{Introduction}

In last decades, the production of permanent magnet (PM) generators has grown rapidly after the invention of the rare earth materials. Today's PMs are especially made by Neodium (NdFeB) magnets for the industrial purposes. $[1,2]$ Axial flux PM generators(AFPMGs) have in general higher energy densities, lower cogging torque and lower cost, thereby they have been very popular for the energy conversion systems $[3,4]$. On the other hand, the phase voltages generated by PM generators can be obtained as close to ideal sinusoidal waveform [5].

Generators should be efficient and light for easy installation and more durable in its operation time. Although the PM generators are mostly preferred to operate in wind turbines, they are indispensable for hydroelectric and geothermal conversion systems. Here, it should be pointed out that AFPMGs have certain advantages for its low cost, high energy density and robust rotor/stator frame according to the finite element analysis (FEA) $[6,7]$. According to literature, there are many different designs on the PM machines. In the work of Muljadi et al., they designed and implemented a machine with a torus geometry for low

\footnotetext{
$\triangle$ Mustafa İlbaş, ilbas@gazi.edu.tr; Mustafa Demirci, mdemirci66@gmail.com; Erol Kurt, ekurt52tr@yahoo.com | ${ }^{1}$ Department of Energy Systems Engineering, Faculty of Technology, Gazi University, Ankara, Turkey. ${ }^{2}$ Department of Electrical and Electronics Engineering, Faculty of Technology, Gazi University, Ankara, Turkey.
} 
power house-hold wind energy applications [8]. In other work, Gör and Kurt [9] have designed a new 3-phase generator with power scale of $250 \mathrm{~W}$. In the literature, one of the important issues is the losses of the generator. In 2008, Marignetti et al. studied the soft magnetic material core for their axial flux machine, they explored the losses and also thermal issues of the machine [10]. In Ref. [11], Scowby et al., discussed a special machine with a $300 \mathrm{~kW}$ power at $2300 \mathrm{rpm}$ and they thermally modelled their structure for different conditions. In a different thermal analysis study, the flow rate and temperature values of a prototype machine have been measured [12]. In another paper, the methods to calculate rotor eddy current losses have been discussed and harmonic methods are applied to the machine [13]. In 2015, Wrobel et al. [14] studied the heat transfer processes of their PM generator and mechanical losses were also defined.

The losses directly affects the electrical efficiency of a machine. Apart from that, mechanical losses are mainly related to aerodynamic effects, which are hard to detect or needs much effort. In that manner, it is worth to explore the mechanical losses and relevant aerodynamic aspects. Indeed, fundamental applications in this field are the matter of forced convection or liquid cooling systems for machine units. For instance, Howey et al. [15] have studied the convective heat transfer within the air gap of both cylindrical and disk geometry. They claimed that the torque of the machine is limited by the maximum temperature of the components, thereby surface convective heat transfer coefficients are vital. In Ref. [16], Howey et al., performed an experimental and theoretical study on an aircooled disc type machine. In the experimental measurements, thin-film electrical heating method is used. Liu et al. [17] designed and implemented a composite rotor in low air pressure environment. The windage loss predictions were performed and the airgap windage was examined between the rotor and stator in successive spin tests. In the other study [18], El-Refaie et al. studied PM machines for the ground transportation sector. The machine was optimized in terms of thermal management schemes and the advanced rotor structure was ascertained. In one of recent studies, Debruyne and his colleagues have explored the effect of temperature on the line-start permanent-magnet machines efficiency by both finite-element modeling and by practical measurements in a squirrel-cage induction machine [19]. It has been proven that the PM flux density was a function of the operating temperature, thereby the temperature affected almost every electrical quantity of the machine, including current, torque, and efficiency.

In the electromagnetic systems, any overheating due to the electrical and magnetic parts lead to losses or damages. In that manner, especially the temperature of the magnet should be under critical temperature of the rare earth material, otherwise their magnetic characteristics have been annihilated. According to literature, critical temperature of $\mathrm{NdFeB}$ is $\mathrm{T}_{\mathrm{c}}=150^{\circ} \mathrm{C}$ [20]. That motivates one to set up a good air or liquid cooling facility for the electrical conversion systems. In terms of thermodynamics, high convection coefficient refers to high cooling ability. Indeed, convection coefficient depends on Nusselt and Reynolds numbers. On the one hand, Reynolds number is also directly proportional to the fluid velocity. This velocity is dependent on the fan rotational speed and characteristics of the fan blade such as its shape, blade number and pitch in the cooling system [21].The axial fan has a wide range of application for cooling purposes due to its basic, closed-pack structure and low cost. In order to design and implement such a fan, computational fluid dynamics (CFD) simulations are the best way in order to reduce the production costs and obtain the most optimal geometry, thereby fluid flowing through the axial fan and stator components can be tested to achieve better aerodynamics. The CFD techniques are faster and cheaper than any experimental procedure, thus they are inevitably applied for the machine design [22]. It should be also pointed out that axial flow machines generally have lower specific energy and superior flow rate because their specific velocity is high and specific diameter is low on a single-stage base $[23,24]$. Naturally, the axial flux machines produce a centrifugal force on the fluid and that is also combined with the fluid flowing through the blades.

In the present paper, a new fan structure for the rotor unit of a wind energy generator has been designed and simulated. In the previous papers, there is no sufficient study on the blade number and blade angle parameters for other axial flux machines to our knowledge. Since our PM generator is a new machine, the blade numbers and blade angles should be ascertained in order to have an effective air cooling process. Therefore, we have motivated ourselves to perform this study as a new contribution to the literature. In the generators, especially the volume of the rotor is restricted due to the rotational aspects of the magnets. Therefore, an efficient CFD analysis for that restricted volume gets importance in order to get maximal efficiency in cooling. Since the rotor structure of the generator is novel, a novel design for the blades is required. It will be shown that velocity and pressure profiles strictly depend on the angle and blade numbers. The paper is formed as follows: The methodology is described in Sect. 2 . The computational dynamic domain, the structure and the mesh optimization are given in this section. In the following section, the main simulation results and relevant discussion exist. The angles and blade numbers are the main operational parameters to test in that section. Velocity and pressure profiles are also examined in that section. The final remarks are given in the conclusion section. 


\section{Materials and methods}

\subsection{Model validation}

In this study, performance of rotor fan is observed and explored for the cooling purpose of the generator. For this reason, the experimental setup is prepared. The number of blades of rotor fan is 16 , the thickness of blades is $5 \mathrm{~mm}$ and the blade angle of the rotor fan is 65 degree in the experiment. The fluid velocity measurements have been performed with the use of an anemometer placed $1 \mathrm{~cm}$ away to the rotor fan. Anemometer type is hot wire with a nominal accuracy of $\pm \% 5 \mathrm{~m} / \mathrm{s}$. The experimental setup can be seen in Fig. 1.

The initial experimental results are received from three different locations in the tests: The blade root, blade tip and position with 2.5 and $5 \mathrm{~cm}$ away from rotor. The machine has been operated at $700 \mathrm{rpm}$ and the results are depicted in Fig. 2. Note that the experimental results are compared with the findings from the numerical simulations. It has been proven that the results of simulation are in good agreement with the experimental findings especially for low speed regime. Therefore, the simulations can be used for further exploration of other parameters on the blade performances.

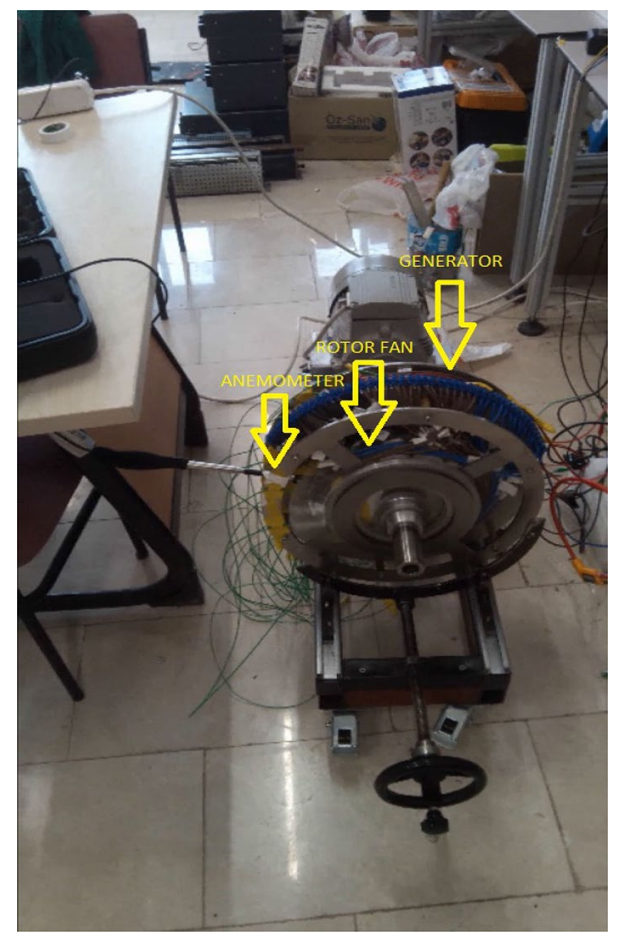

Fig. 1 Experimental setup

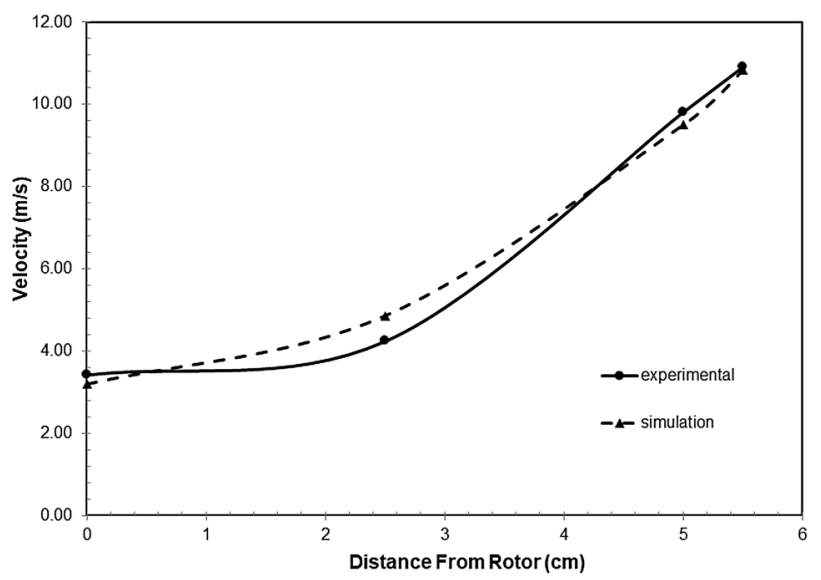

Fig. 2 Validation of simulations via the experimental and simulation results for blades length

\subsection{CFD modeling}

CFD is mainly performed in all geometries including the simple ones such as flat sheets and circular tubes and complicated ones. The flow zone is divided into certain small mesh regions. The meshes should be smooth and include the solutions of the differential equations of the relevant fluid. The mesh elements should be smaller around the complicated geometry parts and especially edge regions of the studied structures. The solutions can be obtained by serial iterations and the Navier-Stokes equations including the continuity, momentum, energy for each unit can be solved for each mesh node. If it is desired, the turbulent viscosity can also be added to the model as in the present study by the determination of the turbulent kinetic energy $k$ and the turbulent dissipation ratec. Mesh type is automatically selected as tetrahedral mesh structure by Ansys-Fluent in order to optimize the calculation time. The calculation domain has been determined depending on the generator geometry.

The diameter of the rotor is $D=0.34 \mathrm{~m}$ and the thickness is $0.01 \mathrm{~m}$. In this study, blades length is $0.055 \mathrm{~m}$ and chords length depends on angle of rotor blades. They change from $0.0576 \mathrm{~m}$ for 10 degree to $0.0101 \mathrm{~m}$ for 80 degree. The rotor has been specially designed for the ventilation and cooling applications of a generator, such as the ones used on vertical axis wind turbines (VAWT). The geometry and mesh domain could be seen in Fig. 3 .

In the simulations, default mesh values of ANSYSFluent package have been used. However, one should test whether the mesh numbers are sufficient or less. At this point, when mesh number increases, solution time increases substantially and the computer processor is forced. Another point is that the mesh independence should be ascertained to get the ideal simulation results. 


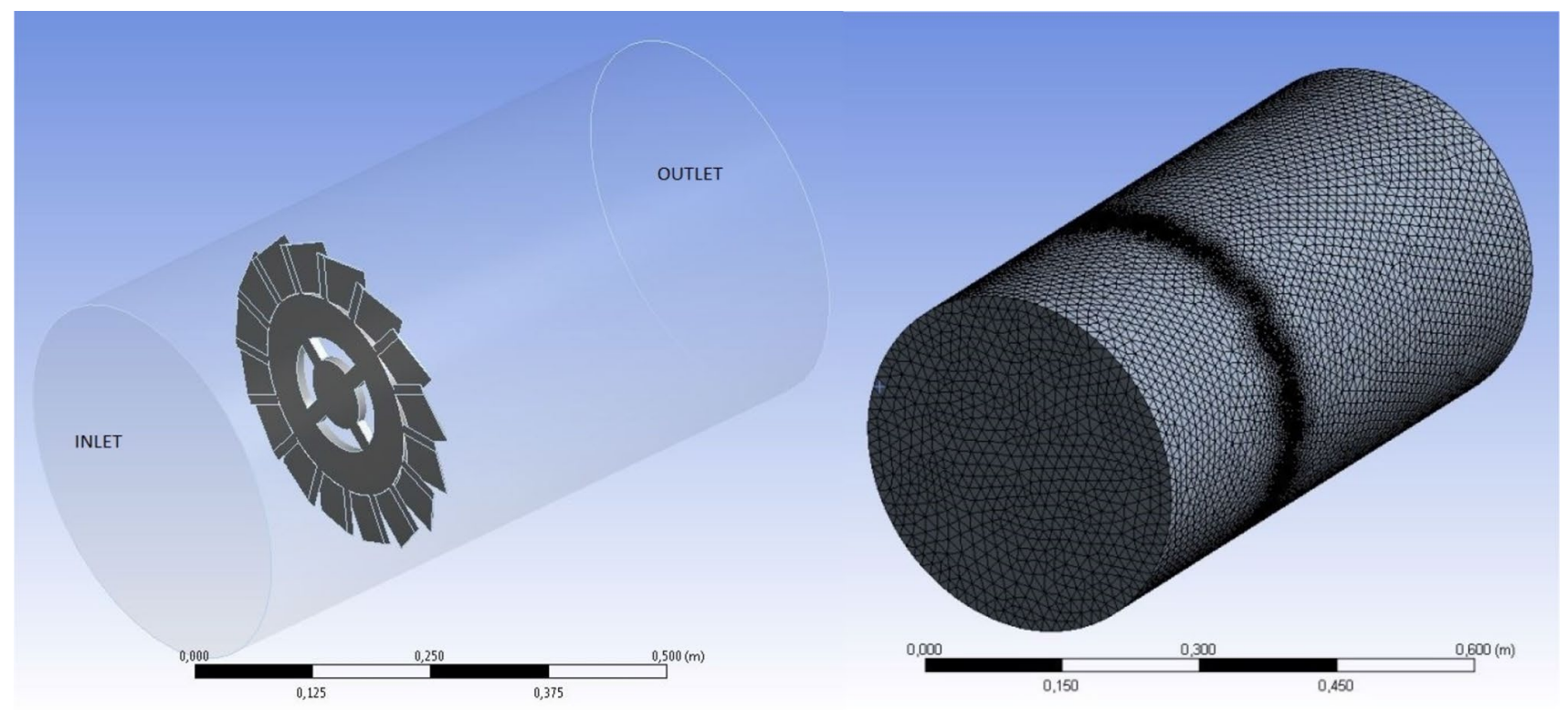

Fig. 3 Axial flow fan rotor geometry and domain

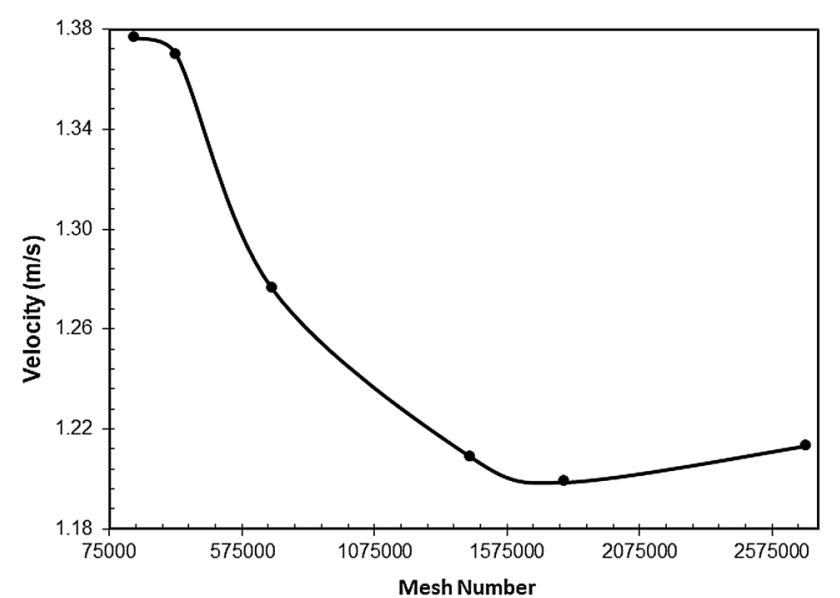

Fig. 4 Mesh Independence for reference points for average velocity

If mesh number is increased, the results become similar to the experimental data as shown in Fig. 4. According to the figure, the most relevant simulation data is obtained for the mesh number $1,439,434$.

\section{Results and discussions}

In this study, formula of the Reynolds Number and fan power is important. Because Reynolds Number is used for limit of flow structure and power is shown consumption of rotor fan. Thus, formula of the Reynolds Number and fan power can be stated as follows over the control volume:

Formula of Reynolds Number:
$\operatorname{Re}=\frac{\rho V D}{\mu}$

Formula of Fan Power:

$\frac{d W}{d t}=\Delta P Q$

Here Re, $\rho, V, D, \mu, \frac{d W}{d t}, \Delta P$ and $Q$ denote Reynolds Number, density, velocity, diameter of domain, viscosity, fan power, pressure difference and volumetric flow rate respectively. For Re is approximately 60.000 at the first formula for $300 \mathrm{rpm}$ angular velocity. If Re is higher than 4.000 for inner pipe, the flow is turbulence. Because in this study, $\mathrm{k}-\varepsilon$ turbulence model is selected in the Ansys-Fluent package program. The simulation time for a parameter set gets almost $12 \mathrm{~h}$ for the simulation computer.

\subsection{Effects of angle of rotor blades}

High velocity is important for good forced convection, because convection coefficient is directly proportional to Reynolds number that is to say velocity. In this study, different angle of rotor blades and chord length are investigated in order to fluid velocity and flow phenomena. In Fig. $5 a, b$ and $c$, the findings for velocity, pressure difference and power are plotted. The velocity amount increases depending rise of angle of rotor blades. Strictly speaking, the velocities get value from 0.46 to $1.86 \mathrm{~m} / \mathrm{s}$. For all those Ansys Fluent simulations, the boundary conditions for the inlet and outlet are taken as stagnant, zero velocity and pressure. Velocity take maximum value at 65 degree 


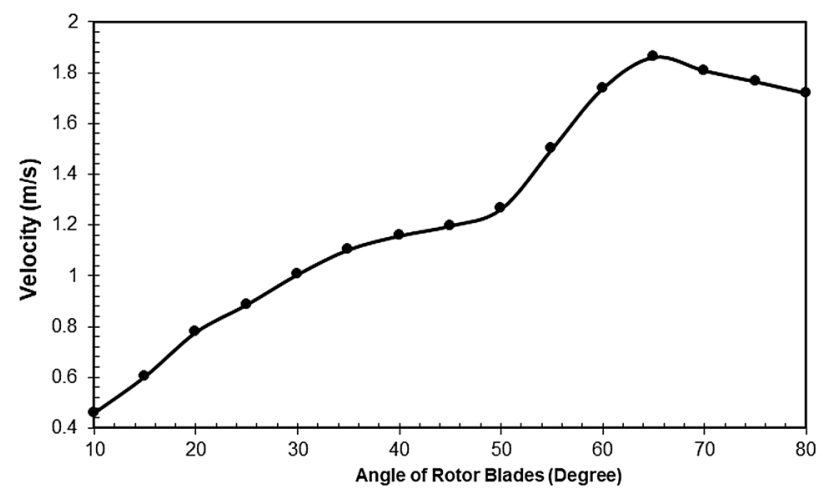

(a)Air Velocity Graphic

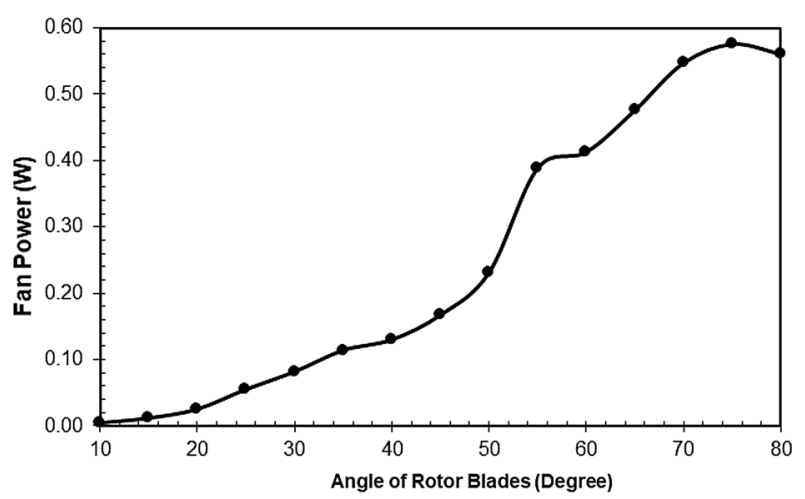

(b) Fan Power Graphics

Fig. 5 Plots of $\mathbf{a}$ air velocity depending angle of rotor blades and $\mathbf{b}$ power with respect to the angle of rotor blades

of angle of rotor blades, it could be seen at the Fig. 5 a. According to Fig. 5b, the fan power for different angle of rotor blades starts from $0.004 \mathrm{~W}$ and increases up to $0.58 \mathrm{~W}$ for 10 degree to 80 degree of rotor blades.

\subsection{Effects of angular velocity}

When the looking at Fig. 6 , it is easily said that just now proposition is proven. Angle of rotor blades is 45 degree and 16 blades rotor fan is selected for investigation of this case. Because its results are the best at before case. According to Figure, the fan power for different angle of rotor blades starts from $0.17 \mathrm{~W}$ and increases up to $29.11 \mathrm{~W}$ for $1500 \mathrm{rpm}$ angular velocity of rotor blades. If the angular velocity rises, fan power is also rises. That is expected result.

\subsection{Effects of number of blades}

In the last case, effect of change of blade numbers of fan is investigated. In this case, angle of rotor blades is 45 degree and angular velocity of rotor is $300 \mathrm{rpm}$. Number of blades is varied between 16 and 56 increased by 8 for impact of

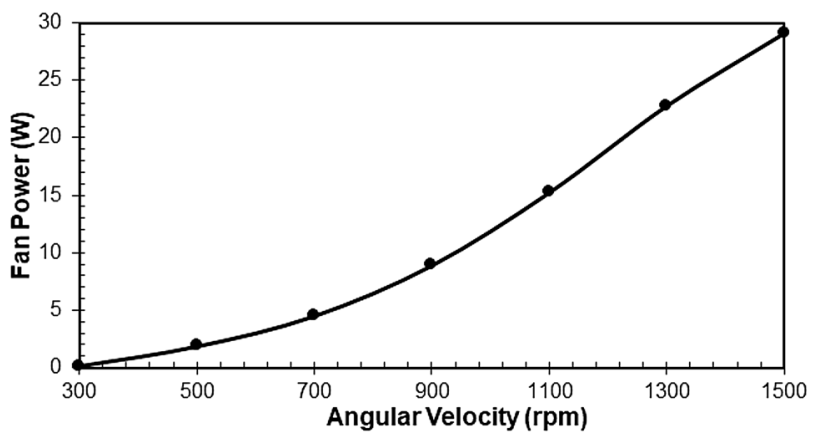

Fig. 6 Plots of power with respect to the angular velocity

number of blades on fluid velocity and fan power. Result of this study graphics are shown in Fig. $7 a$ and b. In the Fig. $7 b$, It could seen easy when more and more number of blades, power increase. In the Fig. $7 a$, fluid velocity increase with 16-40 number of blades, fluid velocity decrease with $40-48$ and it once again increase $48-56$, but fluid velocity is lower of fan with 56 blades is compared to 40 blades. According to this study, it could be easily said that more number of blades is not advantage for good and all.

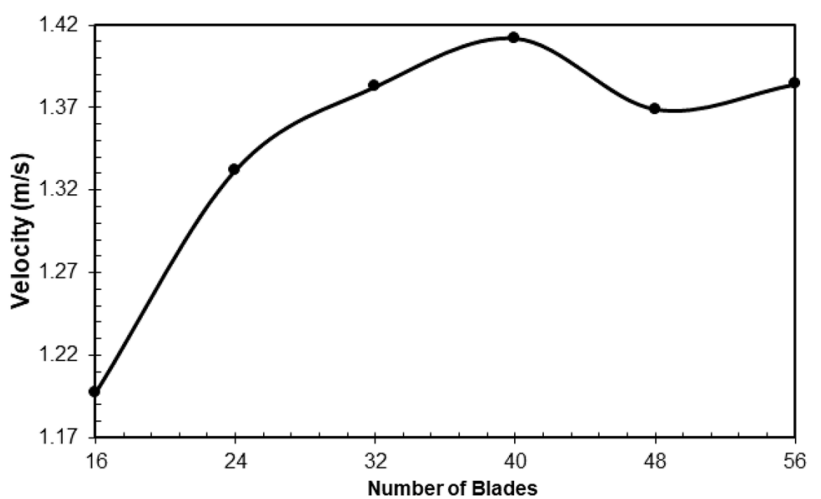

(a) Air Velocity Graphic

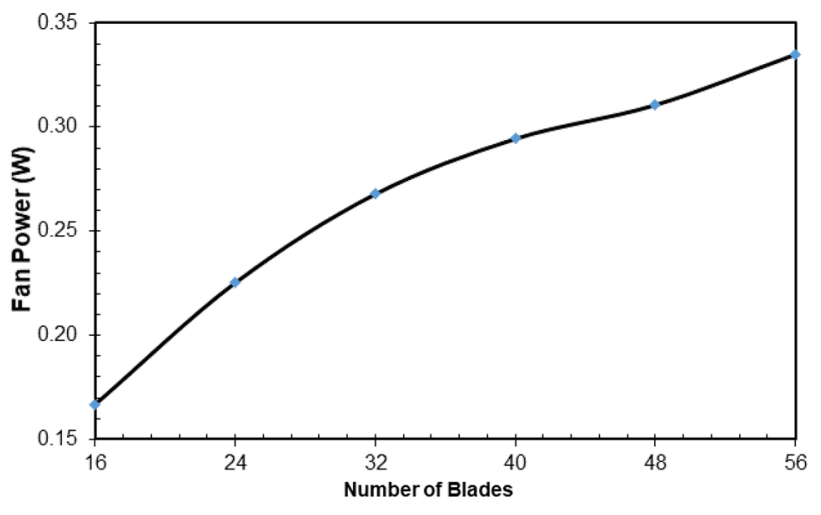

(b) Fan Power Graphics

Fig. 7 Plots of $\mathbf{a}$ air velocity depending blade numbers and $\mathbf{b}$ power with respect to blade numbers 


\section{Conclusions}

The optimized blade structure has been designed for the rotor component of the three phase permanent magnet generator. In the finite element simulations, especially the aerodynamic behavior of the rotor structure has been defined by the number and angle of the blades. The resulting axial rotor fan has been finalized for the self-cooling purposes for the new-designed machine. While the boundary conditions for the inlet are described with zero for velocity and pressure, the outlet has been described with zero pressure. The air velocities have been obtained between 0.46 and $1.86 \mathrm{~m} / \mathrm{s}$ for 10 degrees and 80 degrees, respectively. In addition, the fan power values are found as $0.004 \mathrm{~W}$ and $0.58 \mathrm{~W}$ for the same blade angles. The optimized angle has been determined as 65 degrees. In addition, powers change from 0.17 to $29.11 \mathrm{~W}$ between the angular velocities of $300 \mathrm{rpm}$ and $1500 \mathrm{rpm}$, respectively. The increase in fan velocity produces higher power as usual. In the last simulation set, different blade numbers are simulated. The air velocity has been found between 1.20 and $1.42 \mathrm{~m} / \mathrm{s}$ and the fan power gives the values of $0.17 \mathrm{~W}$ and $0.33 \mathrm{~W}$. The optimum blade number has been simulated as 40 at the end of these simulations.

Acknowledgements The authors present their acknowledgments to TUBITAK for the 1003 Project support under the Project Grant No. $315 \mathrm{M} 483$.

\section{Compliance with ethical standards}

Conflict of interest The authors declare that they have no competing interests.

\section{References}

1. Yıldırız E, Aydemir MT (2009) Analysis, design and implementation of an axial flux, permanent magnet machine to be used in a low power wind generator. J Fac Eng Archit Gazi Univ 24(3):525-531

2. Gör H, Kurt E (2018) Effects of back iron components on efficiency and generated power for new wind energy generators. Electr Power Compon Syst. https://doi.org/10.1080/15325 008.2018.1488013

3. Barave SP, Chowdhury BH (2009) Optimal design of induction generators for space applications. IEEE Trans Aerosp Electron Syst 45(3):1126-1137

4. Singh BP, Dwivedi SA (2006) A state of art on different configurations of permanent magnet brushless machines. J Inst Eng (India). Electr Eng Div 87:63-73

5. Kurt E, Gör H, Döner U (2016) Electromagnetic design of a new axial and radial flux generator with the rotor back-irons. Int J Hydrog Energy 41(17):7019-7026

6. Guannan D, Haifeng W, Hui G, Guobiao G (2010) Direct drive permanent magnet wind generator design and electromagnetic field finite element analysis. IEEE Trans Appl Supercond 20(3):1883-1887

7. Chan TF, Lai LL, Shuming X (2009) Field computation for an axial flux permanent-magnet synchronous generator. IEEE Trans Energy Convers 24(1):1-11

8. Muljadi E, Butterfield CP, Yih-Huie W (1999) Axial-flux modular permanent-magnet generator with a toroidal winding for windturbine applications. IEEE Trans Ind Appl 35(4):831-836

9. Gör H, Kurt E (2016) Preliminary studies of a new permanent magnet generator (PMG) with the axial and radial flux morphology. Int J Hydrog Energy 41:7005-7018

10. Marignetti F, DelliColli V, Coia Y (2008) Design of axial flux PM synchronous machines through 3-D coupled electromagnetic thermal and fluid-dynamical finite-element analysis. IEEE Trans Ind Electron 55(10):3591-3601

11. Scowby S, Dobson R, Kamper M (2004) Thermal modeling of an axial flux permanent magnet machine. Appl Therm Eng 24(2):193-207

12. Wang R, Kamper M, Dobson R (2005) Development of a thermofluid model for axial field permanent-magnet machines. IEEE Trans Energy Convers 20(1):80-87

13. Atkinson GJ et al (2006) The analysis of loss in high-power faulttolerant machines for aerospace applications. IEEE Trans Ind Appl 42(5):1162-1170

14. Wrobel R, Vainel G, Copeland C, Duda T, Staton D, Mellor PH (2015) Investigation of mechanical loss components and heat transfer in an axial-flux PM machine. IEEE Trans Ind Appl 51(4):3000-3011

15. Howey DA, Childs PRN, Holmes AS (2012) Air-gap convection in rotating machines. IEEE Trans Ind Electron 59(3):1367-1375

16. Howey DA, Holmes AS, Pullen KR (2011) Measurement and CFD prediction of heat transfer in air-cooled disc-type electrical machines. IEEE Trans Ind Appl 47(4):1716-1723

17. Liu HP, Werst MD, Hahne JJ, Bogard D (2005) Investigation of windage splits in an enclosed test fixture having a high-speed composite rotor in low air pressure environments. IEEE Trans Magn 41(1):316-321

18. El-Refaie M et al (2013) Advanced high power-density interior permanent magnet motor for traction applications. Proc IEEE ECCE 2013:581-590

19. Debruyne C, Sergeant P, Desmet J, Vandevelde L, Derammelaere S, Pyrhönen J, Polikarpova m (2014) Evaluation of the efficiency of line start permanent magnet machines as function of the operating temperature. IEEE Trans Ind Electron 61(8):4443-4454

20. Chikazumi S (2009) Physics of ferromagnetism, 2nd edn. Oxford University Press, Oxford. ISBN 9780198517764

21. Chen W, Liu S, Gao Y, Zhang H, Arens E, Zhao L, Liu J (2018) Experimental and numerical investigations of indoor air movement distribution with an office ceiling fan. Build Environ 130:14-26

22. Prachar A (2016) Comparison of axial fan rotor experimental data with CFD simulation. Acta Polytech 56(1):62-66

23. Fernandez-Gamiz U, Demirci M, İlbaş M, Zulueta E, Ramos JA, Lopez-Guede JM, Kurt E (2017) Computational characterization of an axial rotor fan. J Energy Syst 1(4):129-137

24. Bouloukza I, Mordjaoui M, Kurt E, Bal G, Ökmen c (2018) Electromagnetic design of new radial flux permanent magnet motor. J Energy Syst 2(1):13-27. https://doi.org/10.30521/jes.397836

Publisher's Note Springer Nature remains neutral with regard to jurisdictional claims in published maps and institutional affiliations. 